\title{
ANÁLISIS DOGMÁTICO SOBRE LA DESFORMALIZACIÓN DEL PROCESO JUDICIAL DE FAMILIA CHILENO. PARTE FINAL
}

[A Dogmatic Analysis on the Deformalization of Chilean Legal Proceedings on Family Matters. Final Section]

\author{
Francesco Carretta MuÑoz* \\ Pontificia Universidad Católica de Valparaíso, Chile
}

\begin{abstract}
RESUMEN
Se examina la noción de desformalización del procedimiento que es uno de los mecanismos adjetivos introducidos por la ley 19.968 para lograr la adecuada tutela de los derechos de familia e infancia. Este segundo enfoque, de otro introductorio ya concluido, intenta cumplir los objetivos trazados en el pri-
\end{abstract}

\begin{abstract}
Is examined the possibility of relaxing the procedural forms. This is one of the adjectives mechanisms introduced by Law 19.968 to ensure the adequate protection of the rights of families and children in the proceedings before the Family Court. This second approach, another introductory been completed,
\end{abstract}

RECIBIDO el 21 de septiembre y ACEPTADO el 7 de diciembre de 2015

* Profesor agregado de derecho procesal civil de la Facultad de Derecho de la Pontificia Universidad Católica de Valparaíso. Dirección postal: Facultad de Derecho, Pontificia Universidad Católica de Valparaíso, Casilla 4055, Valparaíso, Chile. Correo electrónico: francesco.carretta@ucv.cl. Este trabajo fue realizado en el marco y con el financiamiento del proyecto Fondecyt iniciación $\mathrm{N}^{\circ}$ 11130404, titulado: "Estudio sobre la desformalización del proceso judicial de familia e infancia, de cara a su adecuada interpretación y aplicación en la justicia de familia chilena", del cual el autor de este trabajo es su investigador responsable. El autor agradece especialmente a los profesores Bruno Caponi, de la Università degli Studi di Firenze, y Jordi Nieva Fenoll, de la Universidad de Barcelona. A Susan Turner, Daniela Accatino, Andrés Bordalí, Yanira Zúñiga, Iván Hunter, José Ángel Fernández Cruz y Álvaro Núñez Vaquero, de la Universidad Austral de Chile, y a don Darío Carretta, por sus comentarios, que sin duda han servido para mejorar los resultados de esta segunda parte. 
mero, a través de un estudio dogmático y comparado sobre el instituto. Además contiene la reseña de una prospección aplicada relacionada al mismo.

PaLABRAS ClAVE

Procedimiento de familia - Formas procesales - Principios. tries to meet the goals in the first, through a dogmatic and comparative study on the institute. There is also the review of empirical research related to it.

\section{KEYWORDS}

Family procedure - Procedural Forms - Principles.

\section{INTRODUCCIÓN}

Esta investigación tuvo como punto de partida una situación que pude apreciar en mi experiencia como juez de familia, a raíz de lo que me comentó un abogado que ejerce libremente su profesión. Él me señaló que luego de ratificar su demanda en la audiencia preparatoria, confiado en que su contraparte no había contestado en tiempo y forma, es decir, cinco días antes de la misma, su contendor comenzó igualmente a responder oralmente, sin que el juez hiciese cuestión de aquello. Entendía que la carga procesal de su contraria había precluido. Sin embargo, pese a su inmediato reclamo, el juez le dijo: "colega, este procedimiento es desformalizado por lo que su contraparte puede igualmente contestar" y así continuó el demandado hasta completar su exposición. Cualquier lector al igual que yo esa vez, puede quedar sorprendido ante tal situación. Sin embargo, tampoco lograba explicarme muy bien qué había de malo en la resolución del colega. Después de todo, la desformalización evoca una idea similar a la que quiso él representar al resolver de esa manera. Al poco tiempo, indagando las razones de lo acontecido, me di cuenta que el alcance que los jueces de familia confieren a la desformalización es mucho más amplio al que el legislador pretendió otorgarle y produce consecuencias prácticas relevantes. Todos los vértices, causas y efectos de aquel fenómeno fueron pesquisados a lo largo de tres años. Fue imposible publicar todos los resultados en una sola oportunidad, por ello, a esta entrega le precede una parte introductoria ya publicada ${ }^{1} \mathrm{y}$ además un análisis empírico que pasa a constituir un anexo ${ }^{2}$ que sirve como fundamentación de varios de los tópicos que son tratados en adelante.

${ }^{1}$ Carretta Muñoz, Francesco, La desformalización del proceso judicial de familia e infancia, en Revista de Derecho de la Pontificia Universidad Católica de Valparaíso, 42 (2014) 1, pp. 481-495.

${ }^{2}$ Se trata de un estudio aplicado de carácter cualitativo que se realizó mediante 
Esta parte, que pretende cerrar el ciclo sobre la temática que le da origen, intentará cumplir el compromiso que se hizo al final de la publicación introductoria ${ }^{3}$ y completar el sostén teórico que busca responder las hipótesis que originan toda la investigación. Estas son: $i$ ) que la ley en ningún caso señala que la desformalización sea un principio jurídico; ii) que, pese a lo anterior, los jueces de familia la entienden como tal; y iii) que la desformalización es una característica inherente a un procedimiento que busca la tutela de los derechos de la familia y la infancia. Para ello se profundizará sobre la utilidad de las formas procesales y el valor de los principios jurídicos en el sistema de derecho, en confronte a los parámetros que debe tener en cuenta el sentenciador al usarlos, si estima que la desformalización es uno de ellos. También se agrega una reseña de los sistemas español e italiano de similar tradición jurídica al chileno, con el objetivo de dar a conocer las alternativas que ellos han tomado para propender a tutelar de mejor forma los derechos inherentes a la justicia de familia, sin acudir a la desestructuración del procedimiento.

\section{ANÁLISIS EXEGÉTICO DE LA LEY QUE CONTIENE EL MODELO}

Todo este estudio tiene como base lo dispuesto en el artículo $9^{\circ}$ de la Ley $\mathrm{N}^{\circ}$ 19.968: "Principios del procedimiento. El procedimiento que aplicarán los juzgados de familia será oral, concentrado y desformalizado. En él primarán los principios de la inmediación, actuación de oficio y buisqueda de soluciones colaborativas entre partes."

La estructura literal de la norma contiene un epígrafe que dificulta su buen entendimiento. Dice: "los principios del procedimiento", pero en su

el análisis de una muestra que fue tomada el año 2014 a través de entrevistas realizadas a 27 jueces de familia de todo Chile sobre la manera como ellos entienden a la desformalización. Los instrumentos de análisis y la prospección cuenta con la aprobación y certificación ética para el trabajo con humanos del comité de bioética de la Pontificia Universidad Católica de Valparaíso. Toda la información e insumos suministrados por las encuestas anónimas se encuentra bajo custodia del investigador responsable. El resultado del análisis jurídico de las entrevistas y el estudio base que le sirve de fundamento se encuentran, a la época de elaboración de esta obra, en proceso de arbitraje. No obstante, sus ideas y conclusiones matrices se consignan en el capítulo III.

3 "Se consignarán mayores fundamentos teóricos en base al derecho vigente y comparado con el objeto de obtener una mejor profundización y dogmatización de las ideas expuestas. También se darán a conocer los resultados de una prospección elaborada mediante metodología cualitativa, de acuerdo a una muestra tomada a jueces de familia de diversas regiones del país, sobre la forma como entienden y aplican esta figura": Carretta MuÑoz, Francesco, cit. (N. 1), p. 492. 
desarrollo textual describe dos cosas distintas. La clave está en el segundo punto aparte que contiene. Éste separa claramente i) los principios, de ii) las características del procedimiento y, si se lee con detención, la desformalización se ubica dentro del punto 2. De acuerdo a ello, los únicos principios jurídicos que direccionan el procedimiento son la inmediación, la actuación de oficio y la búsqueda de soluciones colaborativas. Lo anterior es el corolario de la historia fidedigna de su establecimiento. Ésta dio cuenta que el legislador no tuvo en mente entregar al juez un principio jurídico a través de la referida figura, por el temor que le generaba que pudiese crear por medio de él trámites o actuaciones no previstas en la ley, lo que en el fondo implicaba una intromisión en atribuciones que no le son propias . Aunque la comisión de la cámara no lo dijo expresamente, se puede presumir que sus temores no son meramente definitorios, sino que se trasladan a los propios vértices de un Estado de Derecho. Por una parte, porque de permitirse soterradamente la creación de la ley por parte de los jueces, el principio de la legalidad resultaría transgredido, y por la otra, porque se dejaría legislar a un órgano que en Chile no es elegido democráticamente en forma directa, con todas las implicaciones que ello conlleva. Además, en un sistema donde es habitual la falta de una ratio jurisprudencial ${ }^{5}$, en que no existen criterios claros ni definidos sobre los alcances y la aplicación de varias normas y figuras, de paso también se lesiona la seguridad jurídica, la confianza legítima y la igualdad ante la ley ${ }^{6}$.

Pese a lo anterior, la jurisprudencia sí le da el valor de un principio jurídico, con el inconveniente de que no existe acuerdo en ella, de los alcances que en el derecho poseen, más allá de que tampoco hay consenso sobre los límites y parámetros de la desformalización, independiente de la consideración inicial que cada juez le pueda dar. Estos desacuerdos judiciales, como se estudiará más adelante, son en una buena medida el reflejo de la indefinición que sobre los principios hay en la doctrina ${ }^{7}$ y el ordenamiento jurídico ${ }^{8}$.

${ }^{4}$ Historia de la Ley $N^{\circ} 19.968$ que crea los Tribunales de Familia, "Segundo informe de la Comisión de Constitución”, Discusión en particular (Valparaíso, 2004), p. 1057, disponible en http://www.bcn.cl/histley/lfs/hdl-19968/HL19968.pdf. Consultada el 12 de septiembre de 2015.

${ }^{5}$ Romero Seguel, A., La jursiprudencia de los tribunales como fuente del derecho (Santiago,Editorial Jurídica de Chile, 2004), pp. 11-15.

${ }^{6}$ Carretta Muñoz, Francesco, La coherencia en el proceso civil (Santiago, Thomson Reuters, 2013), pp. 277-284.

${ }^{7}$ Véase el capítulo cuarto.

${ }^{8}$ Guastini, R., Distinguendo ancora (Madrid, Marcial Pons, 2013), pp. 34-36; AlPA, G., I principi generali (2a edición, Milano, Giuffrè, 2006), p. 7. 


\section{JURISPRUDENCIA}

Un fallo de la Corte de Apelaciones de San Miguel" señaló: "que conforme lo dispone el artículo $61 N^{\circ} 8$ de la ley 19.968, es la audiencia preparatoria la oportunidad procesal para ofrecer y determinar las pruebas que han de rendirse en la audiencia respectiva y sin perjuicio de la facultad que tiene el juez para disponer la práctica de otras que estime pertinente, ello no puede alterar las pruebas ofrecidas, por cuanto lo que el demandante pretendia era que el juez supliera la omisión en que había incurrido al no ofrecer prueba testimonial para acreditar los presupuestos de su pretensión, por lo que no podia rendirse en la audiencia de juicio pruebas que no habian sido debidamente ofrecidas en la audiencia preparatoria". Agregó, que el principio de desformalización vigente en los tribunales de familia "dice relación fundamentalmente con que la actuación procesal queda entregada, dentro de los márgenes que establece la ley, a la libre actuación de los intervinientes". Como se aprecia, para la Corte, la desformalización es efectivamente un principio, y por la aproximación que realiza sobre su contenido, se trata de un principio procesal. El alcance que le confiere en virtud de estimarla como una directriz es que las partes poseen cierta libertad que ha de ejercerse dentro de los márgenes que establece la ley. Pero no específica en qué consiste la "libre actuación de los intervinientes"; cuál es la relación causa y efecto entre la libertad y la desformalización; ni tampoco, como aquella premisa resulta aplicable al caso concreto. Al parecer con ello pretende descartar lo que afirma el apelante, pero como no realiza ninguna precisión, la oración permanece como una cláusula abierta sin contenido tangible, haciendo confusa la catalogación. Lo que en el fondo hace la Corte, más que descartar la aplicación de un principio o describirlo, es asignarle pleno valor a la preclusión como herramienta dentro del proceso que impide volver a ocupar una facultad, en este caso presentar prueba, que ya se consumó por su no utilización en una etapa predeterminada.

Existe otro fallo que resolvió un recurso de apelación que negó lugar a la concesión de una medida legal de retención sobre los dineros que el demandado en un juicio de alimentos percibiría por concepto de desahucio. Se señaló que los procedimientos ante los TF están inspirados en diversos principios, entre ellos, la desformalización: "más que atender a las formalidades tanto en la petición que se hace al tribunal, como en la correspondiente respuesta jurisdiccional, no observaran tanto las formas, sino que lo importante

${ }^{9}$ Corte de Apelaciones de San Miguel, sentencia rol № 415-2010, dictada el 4 de octubre de 2010 (ID CL/JUR/8075/2010). Disponible en www.legalpublishing3.cl [consultada el 12 de septiembre de 2015]. 
es el fondo del asunto sometido a la resolución del juez, que resguardando los derechos de todos los intervinientes, implique satisfacer el interés superior que la ley se encarga de resguardar. Y asi la actuación procesal queda entregada dentro de los márgenes que establece la ley a la libre actuación de los intervinientes" $"$. Esta sentencia que establece la íntima relación existente entre el derecho sustantivo y el derecho adjetivo, resulta paradojal. Ello, porque aquella "libre actuación" que predica, se contradice con los márgenes certeros que la ley procesal, en tanto pública, impone. Se debe recordar que en este ámbito solo es posible ejecutar aquellas acciones que la ley expresamente dispone. Así la libertad no es tal. La desformalización no despliega un margen discrecional de conductas que las partes y el juez pueden realizar, sino que se circunscribe a un catálogo de hipótesis concretas plasmadas específicamente en la ley. La Corte parece decir que el fondo del asunto, en este caso, que asimila al "interés superior de la ley", puede pasar por alto la forma procesal, lo que no es correcto. No es posible que a través de un principio el juez pueda crear un trámite procesal fuera de la ley, que en sustancia es lo mismo que omitir uno existente, ya que en la omisión se está creando una forma novedosa.

Otra sentencia de la Corte de Apelaciones de Concepción, señaló: "Que, establecido que la demandada no se encontraba en situación de indefensión, por cuanto ya habia tomado conocimiento de la demanda, a lo menos el 2 de abril de 2009 y que, la continuación de la audiencia preparatoria celebrada el día 17 de abril de 2009 quedó fijada para el 7 de mayo de 2009, por lo que contó con un plazo aun mayor del que la Ley establece para preparar sus defensas, lo que lleva a concluir que la realización de esta audiencia del 7 de mayo de 2009 sin la presencia de la demandada no es imputable a un vicio procesal de aquellos que autorizan la nulidad, sino sólo a su voluntad de asilarse en una ritualidad formal, rígida y desplazada ya definitivamente de los nuevos procedimientos, no se hará lugar a la casación impetrada" 11. El tribunal de casación agregó, "Sostener la hipótesis de la recurrente sería, en cambio, traicionar los principios del procedimiento concentrado y desformalizado que se ha establecido para los Tribunales de Familia". Por estas consideraciones, entre otras, se desestimó la casación de forma deducida. El tribunal no admitió la argumentación del recurrente, estimó que la ritualidad formal infringida no tiene la entidad para constituir un vicio

${ }^{10}$ Corte de Apelaciones de San Miguel, sentencia rol N ${ }^{\circ} 218-2010$, considerando $8^{\circ}$, dictada el 10 de mayo de 2010 (ID CL/JUR/2564/2010). Disponible en www. legalpublishing3.cl. [consultada el 12 de septiembre de 2015].

${ }^{11}$ Corte de Apelaciones de Concepción, sentencia rol No 433-2009, dictada el 22 de abril de 2010 (ID CL/JUR/2746/2010). Disponible en www.legalpublishing3.cl [consultada el 12 de septiembre de 2015]. 
procesal que autorice la declaración de nulidad. De esta manera estimó que en los procedimientos ante los tribunales de familia las ritualidades han sido desplazadas por formas revestidas de una mayor flexibilidad, atendiendo más al fin del proceso que al cumplimiento de la forma misma.

Se planteó un recurso de protección en contra de una resolución dictada por un juez, por haber decretado cautelarmente la suspensión del derecho de visitas por escrito y fuera de audiencia, en circunstancias que para el caso la ley (artículo 26 LTF.) no lo permite ${ }^{12}$ El magistrado informó que para tal efecto (omitir el margen legal expreso) tuvo como fundamento la Ley $\mathrm{N}^{\circ} 19.968$, que precisan, en su artículo 9, entre otros principios del procedimiento, la desformalización. En ese tenor, es de suponer que para el magistrado sería posible no seguir el límite que impone la ley, en pos del principio. Pero si bien aquella actuación del juez en determinadas circunstancias, de acuerdo a la disposición legal citada puede ser posible, es erróneo para ello invocar aquel supuesto principio como un justificativo. La potestad cautelar contenida en el artículo 22 es suficiente y conlleva, atendida su amplitud, a la desformalización como parte de su estructura.

La Corte de Apelaciones de Santiago consignó en un fallo que: "en materia de procedimiento de familia, opera el principio de la desformalización, lo que significa que los asuntos que conoce este tipo de tribunales no está sujeto a ritualidades estrictas, puesto que, la mayoría de las veces los usuarios del sistema no están acompañados de personas letradas -quienes bien saben lo que debe hacerse y decirse en la audiencia- $y$ desconocen lo complejo de la terminología, por lo tanto, ésta se acomoda a sus necesidades y a su nivel de conocimiento, porque el sistema está al servicio del usuario que necesita cautela jurisdiccional y no para complicarlo, de tal modo que, la omisión de la ratificación nunca podrá comprometer todo el proceso, y menos, el fallo que se dicte en virtud de él"13.

En el mismo sentido que se ha tratado de plasmar en este acápite, se pronuncian otras sentencias ${ }^{14}$.

${ }^{12}$ Corte de Apelaciones de Punta Arenas, sentencia rol No $79-2007$, dictada el 10 de diciembre de 2007 (ID CL/JUR/251/2007). Disponible en www.legalpublishing3.cl. [consultada el 12 de septiembre de 2015].

${ }^{13}$ Corte de Apelaciones de Santiago, sentencia rol No 2916-2007, dictada el 30 de octubre de 2007 (ID CL/JUR/121/2007). Disponible en www.legalpublishing3. cl. [consultada el 12 de septiembre de 2015].

${ }^{14}$ Véase: Corte Suprema, sentencia de 30 de octubre de 2007, en BARrientos Grandon, J., El código de la familia (Santiago, Thomson Reuters, 2009), p. 556; Corte de Apelaciones de Santiago, sentencia rol No 4331-1998, de 17 de marzo de 1999 (ID 20677); Corte de Apelaciones de Puerto Montt, sentencia de 30 de agosto de 2010 (ID 47003); Corte de Apelaciones de Concepción, sentencia rol N ${ }^{\circ}$ 


\section{ENTENDIMIENTO DEL MODELO POR PARTE DE LA JUDICATURA. EXAMEN APLICADO}

Reflejo de la jurisprudencia es la práctica de los tribunales. Entre el año 2014 y 2015 se realizó una investigación aplicada sobre el entendimiento que 27 jueces de diversas regiones de Chile tienen sobre la desformalización y los usos efectivos que ejecutan en base a esa comprensión en el procedimiento de familia. No se trató de un estudio estadístico, sino que cualitativo. En ese sentido, se intentan reflejar tendencias que un grupo de jueces poseen sobre el tópico, que permiten visualizar cuáles son las razones por las que ellos toman las decisiones que toman y, si es posible, presumir una proyección general de cómo ven los jueces chilenos el concepto en estudio ${ }^{15}$.

Previamente fue necesario cotejar su percepción de sentido común, a propósito de que en ocasiones los operadores suelen conectar su intuición a las cláusulas abiertas que conforman los principios. Así, una apreciación primaria denota que en su fuero interno el modelo es percibido por los sentenciadores como "un canal de fluidez por donde las riendas del rito procesal se pueden manejar con mayor libertad, en aras a responder con rapidez y eficiencia a las demandas que se les plantean habitualmente. En este sentido se especifica el criterio dado a conocer por ellos en cinco percepciones: i) mayor libertad para fallar sin apego al ritual; ii) las exigencias administrativas son prescindibles; iii) celeridad y fluidez del proceso; $i v$ ) flexibilidad y adaptabilidad; y $v$ ) eficiencia y eficacia de la labor jurisdiccional" ${ }^{\prime 6}$.

Después, dentro un prisma jurídico, a la pregunta: ¡cómo entienden a la desformalización? el 51,8\% de los jueces entrevistados sostuvieron que se trataba de un principio del derecho. Al indagar sobre las texturas de aquella afirmación mayoritaria, en base a interrogaciones más específicas, se evidenció que no existe acuerdo entre ellos de los alcances que una directriz jurídica posee. Dentro de las conclusiones: "se observan jueces que entienden el principio como una técnica interpretativa y otros que la conciben como una fuente normativa" ${ }^{17}$. Luego, al precisar el contenido del modelo, independiente de la consideración forense de cada uno de ellos, se identificaron tres corrientes: $i$ ) la de aquellos que estiman que en virtud de la desformalización pueden actuar libremente para pasar por

2239-2008, de 28 de agosto de 2009 (ID CL/JUR/667/2009); disponibles en www. legalpublishing3.cl. [consultada el 12 de septiembre de 2015].

${ }^{15}$ Véase la nota 2.

${ }^{16}$ Ibíd.

${ }^{17}$ Texto de la conclusión $1^{\text {a }}$ del estudio base. Véase la nota 2. 
alto la preclusión o para permitir que se realicen actuaciones fuera del específico rango legal, reforzando la fundamentación a razones periféricas al Derecho, como la justicia material del caso; ii) la de quienes estiman que la desformalización es un principio, pero que en virtud de él no se pueden pasar por alto las reglas establecidas claramente en la ley. En este caso sería una pauta meramente orientativa; iii) en fin, la de los que consideran que los poderes que asumen conforme a la desformalización los faculta para flexibilizar autónomamente las formas rituales, sin embargo, también creen que si no mediase este modelo, igual pudiesen tener las mismas facultades en virtud del principio de actuación de oficio, al que agregan otras directrices del derecho de fondo ${ }^{18}$.

Esta variedad de interpretaciones y vacilaciones a la hora de aplicar la hipotética directriz y darle contenido es, como ya se expresó, el eco de la incerteza que para la doctrina y el ordenamiento representan las directrices jurídicas. Se examinará a continuación.

\section{IMPLICANCIAS DE LA DESFORMALIZACIÓN COMO UN SUPUESTO PRINCIPIO JURÍDICO}

Si se considera que la desformalización es un principio jurídico, como lo estima una buena parte de la judicatura chilena (véase el capítulo anterior), el operador encargado de aplicarlo en ese carácter, deberá asumir antes una serie de cuestiones teóricas complejas relacionadas a ellos ${ }^{19}$.

Aparte de lo que ya se dijo en el estudio introductorio ${ }^{20}$, los principios son desde el derecho romano un recurso argumentativo y retórico contenido en diversos manuales, que tanto jueces, como juristas y abogados han usado para resolver sus controversias. En diversas fuentes normativas se encuentran referencias difusas a los principios, como valores culturales, ratio de brocardos, alusiones a categorías lógicas, enunciados de valores normativos o como una inducción sacada de un conjunto de normas, etcétera. Se encuentran presentes en todos los sistemas jurídicos occidentales y en el derecho internacional ${ }^{21}$. Desde la perspectiva de la tradición jurídica, en el

${ }^{18}$ Ibíd.

${ }^{19}$ En el primer estudio se tomó partido por una postura bastante definida sobre los principios jurídicos. Sin embargo, ahora es necesario rectificar esa opinión en parte y dejar de manifiesto que sobre ellos no puede establecerse una realidad tan categórica. No obstante, tampoco se pueden perder de vista los objetivos de esta prospección, que hacen inoficiosa una mayor profundización sobre los mismos.

${ }^{20}$ Carretta Muñoz, Francesco, cit. (n. 1), pp. 485-486.

${ }^{21}$ Draetta, U., Principi di diritto delle organizzazioni internazionali (Milano, Giuffrè, 2012), pp. 154-155. 
"case law" 22 se asocian a la discrecionalidad del juez, el valor del precedente y las reglas del razonamiento jurídico ${ }^{23}$. En el sistema continental están previstos en códigos y leyes ${ }^{24}$.

Las complicaciones que se acostumbra a citar por la doctrina son básicamente tres. Primero, que la formulación de un principio jurídico suele ser ambigua, hay un notable problema terminológico ${ }^{25}$. Por ejemplo, se alude a ellos como sinónimos de normas, directrices morales o reglas. Luego, son imprecisos, es decir, no hay certeza sobre su contenido ${ }^{26}$. En este rumbo, se suele mencionar que son demasiado generales. No hay claridad ni acuerdo sobre cuáles son y cuáles son sus alcances ${ }^{27}$. En tercer lugar, su falta de contenido tangible, por una parte, hace imprecisa su utilidad práctica, y por la otra, los conecta con facilidad al sentido común del sujeto. Sucede que hay un prurito de calificar tal o cual corriente jurídica, como el "principio que está envuelto o subyace en tal o cual figura o norma”. Rápidamente cualquier operador se queda con una mirada concreta de aquello que piensa

${ }^{22}$ Malleson, K. - Moules, R., The Legal System (4a Edición, Oxford, Oxford University Press, 2010), pp. 28-29; Cross, R. - Harris, W., Precedente in English Law (Oxford, Clarendon Oxford Press, 1991), pp. 11-12. De alguna manera también se pueden considerar como los estándares sociales y morales a los que debe estar sujeto la "Rule of Law". Donati, A., "Rule of Law", "Comon law". Lineamenti (Milano, Giuffrè, 2010), pp. 18-20; Cogliandro, G., Rule of Law, la possibilità del contenuto morale del diritto (Milano, Giuffrè, 2012), passim.

${ }^{23}$ En el sistema norteamericano y anglosajón, cuyo contenido se entiende amplio, pueden entenderse también como los principios de la interpretación de los estatutos, teniendo en cuenta las características de dicho sistema: "canons of construction" o "principles of statutory interpretation". Véase POSNER, R., Reflections on Judging (Cambridge, Harvard University Press, 2013), pp. 4-6.

${ }^{24}$ AlPA, G., cit. (n. 8), p. 6.

${ }^{25}$ Schauer, F., Playing by the Rules (Oxford, Clarendon Law Series, 1991), pp. 19-24.

${ }^{26}$ Aunque hay que hacer algunas precisiones, según Luzzati se debe distinguir la vaguedad de la generalidad. La primera, se refiere a la incerteza de los vocablos, que cae dentro del ámbito de la lingüística, no es por tanto una cuestión de falta de información de los términos. La generalidad en cambio, sí posee una certeza, pero que es inútil. Ello por cuanto si bien puede ser verdadera en su aserción, lo será sin contener elementos que detallen su contenido, es de esta manera en algún punto banal. Luzzati, C., Principi e principi. La genericità nel diritto (Torino, Giappichelli, 2012), pp. 4-5.

${ }^{27}$ Guastini distingue cuatro desacuerdos existentes en materia de principios: $i$ ) que son aquellas normas consideradas como fundamentales que son dotadas de una importancia especial desde el punto de vista axiológico; ii) si del ordenamiento existen principios implícitos; iii) sobre el modo apropiado de concretizar un principio; y iv) sobre la forma de ponderar dos principios en conflicto. Guastini, R., cit. (n. 8), pp. 34-36. 
se está significando y en poco tiempo, desde la intuición pasa a darle todo tipo de efectos teóricos y prácticos a ese tal o cual ${ }^{28}$.

La relación entre principios y valores también es cercana. Se identifican con aquellos paradigmas ubicuos que se estiman como correctos en una sociedad $^{29}$. Desde aquel vértice su categorización es compleja, puesto que no puede constatarse con exactitud su existencia del enunciado de las normas que parecen predicarlos ${ }^{30}$.

Además se expone por algunos juristas que los principios pueden constituirse en normas jurídicas de carácter general, que por vía inductiva emanan de las reglas y normas legales ${ }^{31}$. También se asocian a la vaguedad de la normas, en tanto se apartan de éstas de un modo pre o meta jurídico.

En síntesis, frente a todas las dificultades anotadas, se puede apreciar que "los principios generan simultáneamente orden y desorden"32. No sólo tienen una función constructiva sino que deconstructiva.

Con lo anterior, tampoco se está diciendo que los principios no existan o que no deban utilizarse, sólo se está precisando que sobre ellos no puede haber una mirada superficial y simple a la hora de su aplicación e interpretación. Tampoco puede idearse un principio donde la ley claramente no lo entrega, como se ha venido explicando ocurre en Chile. El jurista debe detenerse y reflexionar, y con tanta o mayor razón el juez que en ocasiones como esta manifiestan una libertad excesiva frente a los límites que el respeto a la ley impone $e^{33}$, en perjuicio del orden y la coherencia de todos los

${ }^{28}$ La imprecisión, el uso excesivo y contradicción de los principios jurídicos en todo caso no es un reclamo actual. Esser, J., Principio y norma en la elaboración jurisprudencial del derecho privado (traducción de E. Valentí, Barcelona, Bosch, 1961), passim.

${ }^{29}$ Como una exigencia de la justicia, la equidad o alguna otra dimensión de la moralidad: Dworkin, R., Talking Rights Seriously (London, Bloombsbury, 2013), p. 46.

${ }^{30}$ Tales como aquellas que señalan que el comportamiento de las partes en un proceso no deben infringir ciertas pautas que afectan, por ejemplo, la bilateralidad de la audiencia. De aquellas se constata el valor (principio) de la equidad. MACCoRMICK, N., Intitutions of Law (Oxford, Oxford University Press, 2007), pp. 28-30.

${ }^{31}$ Alpa, G., cit. (n. 8), p. 7.

${ }^{32}$ Luzzati, C., cit. (n. 26), p. 17. Sobre el tópico en referencia, considerando que son los jueces llamados a aplicarlos, son ilustradoras las palabras del autor citado a ese respecto: "pocos principios en las manos de quienes saben usarlos convenientemente, son capaces de alterar el sistema y, al mismo tiempo, de infundirle nueva sabia”.

${ }^{33}$ Valen aquí las reflexiones de Posner sobre la excesiva libertad de los jueces frente al sistema de Derecho (Entiéndase por sistema de derecho: formalismo jurídico, razonamiento judicial ortodoxo, el gobierno de las leyes y el imperio de la ley). Sobre esto permítaseme salir momentáneamente de la despersonalización del texto, para reafirmar sus ideas, porque como señala Posner, esto es mayormente entendible por 
aspectos que la misma ley regula ${ }^{34}$. Dos de ellos son la constitución de las formas procesales y la preclusión que son precisamente los que de acuerdo al mal entendimiento de la desformalización, mayormente resultan menoscabados. Ambos modelos serán analizados en los dos acápites siguientes.

\section{LA UTILIDAD E IMPORTANCIA DE LAS FORMAS Y SU CONEXIÓN AL}

\section{CONTENIDO: EXPERIENCIA ITALIANA}

La desformalización no puede referirse a la posibilidad de excluir $u$ omitir las formas del iter procesal, significado al que puede apuntar el prefijo "des". El proceso se construye esencialmente sobre ellas, sin las cuales no hay proceso posible, como las locomotoras que sin rieles son inútiles. El significado del término en referencia apunta a la ductilidad que coincide con el sentido que le han asignado varios de los magistrados que han sido parte del estudio empírico ya referido (véase el capítulo cuarto). Las formas ${ }^{35}$ en sentido procesa ${ }^{36}$ son, aparte del modo como el acto procesal se percibe exteriormente ${ }^{37}$, una garantía del conocimiento

aquellos que ejercen la judicatura, como en mi caso. Los jueces son reacios a manifestar como verdaderamente resuelven los asuntos que se les presentan, sobre todo si sus deliberaciones son en general secretas, y si contestan suelen invocar la respuesta oficial del respeto a la ley o que la sentencia habla por sí misma. A lo anterior, se suma que pareciere que los casos se deciden conforme a los propios gustos o paradigmas de la persona del Juez que luego, en un ejercicio de racionalización, escoge una norma jurídica para la solución del mismo. En lo dicho no hay nada nuevo, esta idea está presente en la teoría jurídica desde hace bastante tiempo en el realismo jurídico, siendo descrita dentro las ideas de Dworkin, y hasta en las del autor citado (Posner), entre muchos otros. Por cierto, esto pertenece a una discusión que escapa a los modestos propósitos de esta obra, pero permítaseme decir, al igual que Posner, que legalismo en su buen sentido, sí existe, pero cada vez retrocede más en pos de una libertad demasiado amplia del juzgador. Posner, R., How Judges Think (Cambridge, Harvard university, 2008), pp. 1-15; DWORKIN, R. cit. (n. 29), pp. 19-34.

${ }^{34} \mathrm{La}$ coherencia es un valor presente en toda la conformación del sistema y estructura del derecho. Losano, M., Sistema e struttura nel diritto. Dalle origini alla scuola storica (Milano, Giuffrè, 2002), I, p. 197; CARRETTA, F., cit. (n. 6), passim.

${ }^{35}$ Carretta, F., cit. (n. 1), pp. 483-485.

${ }^{36}$ Ello porque las formas revisten diversos significados en el ordenamiento jurídico, ya sea en el campo de la teoría general del derecho, véase: Negri, A., Alle origini del formalismo giuridico (Padova, CEDAM, 1962), p. 2-3; el derecho privado: Belvedere, A., Forma, en Iudica, Giovanni - Zatti, Paolo (editores), Trattato di diritto privato (Milano, Giuffrè, 1994), pp. 148-158; como en el derecho anglosajón: Thomas, E. W., The Judicial Process (New York, Cambridge University Press, 2005), pp. 55-56.

${ }^{37}$ Luiso, F., Diritto processuale civile (Milano, Giuffré, 2007), p. 400. 
por ambas partes de las reglas preconcebidas del juego ${ }^{38}$, la transparencia y de la imparcialidad del juez ${ }^{39}$. Esto le otorga al rito un estatus de igualdad per se. El proceso se construye sobre ellas y esto hace que su legitimidad, basada en los componentes señalados, le infunda iguales virtudes a la función pública de administrar justicia ${ }^{40}$.

Su posición jurídica, coordinada al desarrollo del proceso, se asienta en la misión práctica que persiguen, por ello, son vistas como una garantía de los derechos y no como un obstáculo a los mismos. Son, en consecuencia, parte fundamental del proceso. Significan una condición del orden jurídico y también social ${ }^{41}$. La falta de ellas conlleva desorden, confusión e incerteza ${ }^{42}$. Pero, al contrario de las virtudes señaladas, su uso excesivo puede desembocar en un formalismo incomprensible ${ }^{43}$.

Muchas formas están apegadas al tiempo y la tradición, pero aquello que pudo tener una justificación en su época, puede que actualmente no lo tenga. Por ejemplo, en un proceso civil restringir la notificación de las actuaciones a medios lentos y costosos, más allá de atentar contra la economía procesal ${ }^{44}$, no tiene cabida hoy, ya que el avance y fiabilidad de las comunicaciones permite no sentir demasiado temor de que a través de métodos novedosos se infrinja su carácter participativo ${ }^{45} \mathrm{y}$, de paso, la

${ }^{38}$ De alguna manera se quiere significar con esta afirmación que a través de las formas se busca la certeza jurídica como previsibilidad. Pero teniendo en consideración las implicancias que la certeza jurídica, ya sea desde el punto de vista axiológico, como por la ambigüedad del término, reclamada por algunos autores, esta afirmación no puede ser demasiado terminante. GoMeTz, G., La certezza giuridica come prevedibilità (Torino, Giappichelli, 2005), passim.

${ }^{39}$ Comoglio, L. P. y otros, Lezioni sul processo civile (2a edición, Bologna, Il Mulino, 2011), p. 320.

${ }^{40}$ Monteleone, G., Manuale di diritto processuale civile (Milano, Cedam. 2009), I, pp. 290-291.

${ }^{41} \mathrm{La}$ forma es parte integrante y esencial de un proceso. Éste es a su vez, como señalan algunos autores, una técnica de control social y un rito de reconstrucción de vínculos sociales. CADIET, L. y otros, Théorie générale du procès (Paris, Presses Universitaries de France, 2010), p. 289.

${ }^{42}$ Chiovenda, G., Principi di diritto processuale civile (Napoli, Jovene,1965), p. 663.

${ }^{43}$ Chiarloni, S., Ragionevolezza costituzionale e garanzie del processo, en Rivista di Diritto Processuale, 68 (2013) 3, p. 534; DenTI, V., Un progetto per la giustizia civile (Bologna, Il Mulino, 1982), p. 123.

${ }^{44}$ Pues la economía procesal también nace como una necesidad de destrabar el proceso, en miras a una más rápida y eficiente administración de justicia. ComogLIO, L. P., Il principio di economia processuale (Padova, CEDAM, 1980), I, p. 30.

${ }^{45}$ Frassinetti, A., La notificaziones nel processo civile (Milano, Giuffrè, 2012), pp. 1-6. 
bilateralidad de la audiencia. Sin embargo, en esta alternativa se insiste en que debe existir una sabia ponderación entre los riesgos de flexibilizar un eslabón de la seguridad jurídica y las ganancias que, para la tutela de los derechos, se obtienen con dicha elección. En buenas cuentas preguntarse si la opción vale la pena, en base a la importancia del derecho protegido.

La justicia civil italiana en su sentido más amplio ${ }^{46}$, para optimizar la tramitación de los procedimientos que confluyen en los diversos asuntos que la conforman, ha optado por un camino concreto: la consagración de la libertad de las formas. En el derecho italiano se habla de que las formas pueden ser dúctiles siempre y cuando aquello sea acorde a la función social del proceso y los principios Constitucionales de tutela. Se menciona por la doctrina en este sentido la locución "forma-contenido". Forma es el equivalente al aspecto extrínseco o morfológico de los actos procesales y, el contenido es el objetivo de los mismos, ya descrito, que está vinculado a la voluntad de la ley, que se independiza de la voluntad subjetiva del agente del acto ${ }^{47}$. Por ello, lo opuesto: la forma sin contenido, equivale a un mero formalismo, sinónimo de trabas innecesarias para el correcto avance del derecho sustantivo que a través del proceso se ampara ${ }^{48}$. La habilitación legal desde donde arranca esa distinción se encuentra en el artículo 121 del Codice di Procedura Civile italiano ${ }^{49}$, que inaugura el párrafo correspondiente a la regulación de la forma de los actos y resoluciones. Dicha norma posee un encabezado que consagra expresamente la libertad de las formas ${ }^{50}$. Su utilidad se hace efectiva sin más en la eventualidad que la ley no requiere de una forma determinada para la ejecución de un acto. En un sentido similar se identifican otras normas específicas. Por ejemplo, el artículo 156 del mismo cuerpo legal donde se encuentra la nulidad por su incumplimiento, siempre y cuando el acto, aunque erróneo en su producción, no haya igualmente cumplido su objetivo ${ }^{51}$. También del artículo 131 referido a una sentencia, ordenanza o decreto que deben dictarse

${ }^{46} \mathrm{El}$ sentido amplio se refiere a que la justicia civil no debe entenderse referida únicamente al resguardo de los asuntos patrimoniales, sino que también a todos los procedimientos destinados a la tutela de la familia y la infancia.

${ }^{47}$ Comoglio, L.P., cit. (n. 44), p. 321; Balena, G., Elementi di diritto processuale civile (Bari, Cacucci, 2006), pp. 121-122.

${ }^{48}$ Di Benedetto, G. - Bellano, S., I linguaggi del processo (Milano, Giuffrè, 2002), p. 5.

${ }^{49}$ SASSANI, B., Codice di procedura civile e leggi complementari (Milano, Giuffrè, 2014), pp. 3-40.

${ }^{50}$ Véase Martino, R. - PAnZarola, A., Commentario alle riforme del processo civile dalla semplificaziones dei riti al decreto sviluppo (Torino, Giappichelli, 2013); VIOLA, L., La semplificazione dei riti civili (Milano, CEDAM, 2011).

${ }^{51}$ Ibíd., p.n5. 
conforme a lo que la ley prescriba, pero a falta de tal regulación podrán pronunciarse en cualquier forma idónea para lograr su propósito. Dada esta sistematización legal, la doctrina infiere el "principio de derivación de la forma al objetivo del acto" 52 cuyos márgenes delimita al señalar que, en virtud de aquel, no puede permitirse una discrecionalidad incontrolada del juez, porque si así fuere se estaría vulnerando la imparcialidad y objetividad de la función jurisdiccional ${ }^{53}$. Pero aun cuando en el sistema italiano exista legalmente tal posibilidad, ésta conlleva el riesgo de quitar los anclajes necesarios que la misma legislación establece para garantizar la seguridad jurídica. En especial, infringir a la preclusión. Es por ello que los magistrados no pueden tomar tal opción sin prever sus límites, en especial si la facultad autónoma del juez de adaptarlas o ajustarlas, ya sea en base a la finalidad de su contenido como en Italia, como cualquier otra, no está expresamente prevista en el ordenamiento, como sucede en el sistema chileno.

\section{LA DESFORMALIZACIÓN VERSUS LA PRECLUSIÓN}

Hay que considerar que en ningún caso la flexibilidad de las formas rituales da la posibilidad de mermar otros modelos inherentes al proceso como la preclusión. En el estudio aplicado que se reseña en el capitolio tercero, se consignó como la primera, dentro de las 3 corrientes de actuación judicial, que un porcentaje de los jueces examinados no le da valor a tan vital modelo; frente a la opción de favorecer a aquella parte que consideran indefensa. Esto ocurre en la sucesión de etapas que acontecen en la audiencia preparatoria, como cuando se permite incorporar prueba una vez que se cerró dicha oportunidad, o aquella que se hizo referencia en la introducción, en que se permite contestar en audiencia preparatoria a una de las partes, mientras que la ley imperativamente fija otro momento para hacerlo. Todas las elecciones que consideran aquellas aparentes razones de buena voluntad, en realidad constituyen una paradoja: mientras por una parte se piensa favorecer la tutela de los sujetos que un juez estima desvalidos socialmente, por la otra se está afectando el mismo orden social cuando se ocasionan fisuras a la seguridad jurídica ${ }^{54}$. Ello, porque la elección en el fondo pasa por alto aspectos que desconocen el debido proceso. Por ejemplo, la bilateralidad de la audiencia, si a la vez se está afectando el derecho del demandante diligente que interpuso su acción en tiempo

\footnotetext{
${ }^{52}$ Ibíd., p.n5.

${ }^{53}$ Comoglio, L.P. y otros, cit. (n. 39), pp. 320-321.

${ }^{54}$ De SANTIS, F., Riforme processuale e disponibilitá del regime preclusivo, en Studi di diritto civile in onore di Giuseppe Tarzia (2005), p. 2642.
} 
y forma y previó razonablemente que su contendor rebelde, carecería de las ventajas que le hubiese implicado defenderse adecuadamente e incluso reconvenir. No se está en el caso de un analfabeto que concurre a la audiencia de estilo, sin representación letrada, en cuyo caso es factible la suspensión. Pero en ese evento, no lo será por una razón piadosa, reconducida jurídicamente a través de la desformalización, sino que por el vicio que se ocasionó cuando al ser notificado no le fue inteligible que debía contestar en tal plazo y recurrir a la asistencia judicial gratuita. Aquel es un caso de omisión de un trámite esencial por no falta de emplazamiento. Además, ¿puede el sentenciador juzgar la apariencia de un interviniente para determinar cuestiones tan subjetivas como la situación económica del mismo o su desamparo? Este criterio muy conectado al sentido común es inseguro pues se basa en una mera percepción del juez en audiencia. Lo que sucede frente a tales cuestionamientos es que estamos en presencia de las llamadas "razones de justicia material" que habitualmente esgrimen los jueces cuando hacen un uso demasiado consiente de su tradición de cultura $^{55}$ para fundamentar sus fallos, pero este interesante tema se sale de los objetivos que persigue este trabajo. En lo que a ellos concierne, la desformalización en estos casos jugó praeter legem, como un argumento jurídico para crear un trámite no contemplado en la ley: la contestación de la demanda en la audiencia preparatoria y también, infringió abiertamente la preclusión al revivir un plazo que se agotó por no haberse ejecutado el acto dentro de su transcurso.

Luego, los sentenciadores al actuar así, han pasado por alto dos cosas. Una, que tal como a las partes, al juez también le afecta un tipo de preclusión llamada pro iudicato ${ }^{56}$, que le impide volver sobre situaciones ya zanjadas a través de una resolución. Dos, que dichas actuaciones colisionan con la naturaleza misma del modelo y con un trascendente aspecto constitucional. Sobre lo primero, la preclusión o "stoppel" es una figura presente en el estudio del derecho procesal desde sus albores ${ }^{57}$, que se expande a todos los ordenamientos jurídicos continentales, incluso a los

${ }^{55}$ En el sentido que al concepto le otorga el realismo jurídico, el juez como un ser humano cualquiera inserto en la sociedad es, durante el transcurso de su vida, permeado de una serie de factores familiares, político, religioso y de toda índole. De acuerdo a lo que Ross señala: el juez es un "fenómeno cultural". Es natural entonces que en sus juicios algo de ese acervo cultural esté presente. Pero lo que se expone en el texto rebasa el límite natural que expresa Ross, A., On Law and Justice (New Jersey, Clark, 1959), pp. 99-100.

${ }^{56}$ Redenti, E., Diritto processuale civile (Milano, Giuffré, 1957), I, pp. 70-71.

${ }^{57}$ Tesoriere, G., Contributo allo studio delle preclusioi nel proceso civile (Padova, CEDAM, 1983), pp. 25-51; ChIOvENDA, G., Instituzioni di diritto processuale civile (Napoli, Jovene, 1960), I, pp. 319-331. 
de tradición jurídica anglosajona ${ }^{58}$. Sirve esencialmente para mitigar la comúnmente denunciada lentitud de la tramitación de los juicios. Si no mediare, ningún proceso llegaría a su fin, por lo que la máxima preclusión se produce en la sentencia definitiva, a través de la cosa juzgada material ${ }^{59}$. Respecto a lo segundo, su infracción se irradia hasta la Constitución ${ }^{60} \mathrm{si}$ se comprende que cualquier actitud fuera de sus márgenes, transgrede el derecho fundamental que tiene todo ser humano a ser juzgado dentro de un plazo razonable ${ }^{61}$.

Relacionado con lo anterior, dentro de la ya señalada pesquisa empírica, se arguyó por algunos jueces, como un argumento auxiliar (frente a la posibilidad que la desformalización no tuviese cabida), la existencia de razones de economía procesal para temperar el rigor del estricto cierre de etapas rituales. Ello, porque al igual que la desformalización, entienden que la economía procesal busca destrabar trámites inútiles y con ese fin oblitera la posibilidad de una injusta dilación del procedimiento ${ }^{62}$. Pero tampoco se puede pasar por alto la preclusión con este argumento secundario, ya que el único objetivo de la economía es otorgar parceladamente poderes al juez en miras a la eliminación del mero formalismo, lo que incide directamente en un ahorro de tiempo y gastos ${ }^{63}$ en la tramitación del juicio. Siempre que no se mire al proceso como una cuestión que solo

${ }^{58}$ Bone, R., Civil Procedure, The Economics of Civil Procedure (New York, Fundation Press, 2003), pp. 232-259.

${ }^{59}$ Luiso, F., cit. (n. 37), p. 175; SASSANI, B., Impugnativa dell atto e disciplina del rapporto (Padova, CEDAM, 1988), p. 162.

${ }^{60}$ Cfr. Monteleone, G., Preclusioni e giusto proceso: due concetti incompatibili, en Bongiorno, G. (editor), Studi in onore di Carmine Punzi (Torino, Giappichelli, 2008), pp. 413-422.

${ }^{61}$ Específicamente a la garantía comprendida en el artículo 19 no 3 inciso quinto de la Carta fundamental y en forma explícita en el artículo 8 de la Convención Americana sobre derechos humanos. Si bien los autores que comentan esta garantía hacen alusión al proceso penal, no se ven razones para que no sea extensible al proceso civil y con mayor razón al de familia si la tutela de los derechos en juego, posee igual o mayor importancia que los que se cautelan en la persecución criminal.

${ }^{62}$ En contraposición al formalismo que atenta contra dicho valor. CHIARLONI, S., cit. (n. 43), p. 513.

${ }^{63} \mathrm{La}$ economía procesal en el ordenamiento italiano puede traducirse en una forma muy concreta de análisis de las normas procesales que regulan la actividad de los intervinientes. Se vierte sobre la buena práctica que los jueces y abogados hacen de figuras procesales, como uno de los principales factores de eficiencia procesal. Véase Dalla Massara, T. - Vaccari, M. (editores), Economia processuale e comportamento delle parti nel processo civile (Napoli, Jovene, 2012). 
incumbe a las partes ${ }^{64}$, sino como un instrumento de progreso social ${ }^{65}$. Por ello, si bien puede notarse cierto parentesco entre ambos mecanismos, a diferencia de la desformalización, la economía procesal es sin lugar a dudas un principio jurídico consagrado en la ley 19.968, bajo el rótulo de "actuación de oficio" (artículo 13) que entrega un margen de actuación al juez. Éste consiste en adoptar de oficio todas las medidas necesarias para llevarlo a término con la mayor celeridad. Con ese objetivo: "deberá dar curso progresivo al procedimiento, salvando los errores formales y omisiones susceptibles de ser subsanados".

\section{Derecho comparado: ITALia y España}

Las opciones del derecho comparado para la optimización de la justicia de familia no han ido por la consagración de principios, sino por caminos legislativos concretos. La justicia italiana de similar tradición jurídica que la chilena, optó por reducir los trámites y complejidades innecesarias de sus procedimientos. La denominada "simplificación del rito", se introduce al ordenamiento italiano con la esperanza de mejorar el fenómeno global del lento devenir de la justicia ${ }^{66}$ y constituye una reforma ${ }^{67}$, dentro de una serie de otras ${ }^{68}$, que apunta al desarrollo de un proceso eficiente. Consiste a grandes rasgos en la reducción de trámites del rito civil en todos sus

${ }^{64}$ Entendido el proceso como un instrumento público de resolución de conflictos, se habla por algunos autores de la relatividad de las formas procesales, en relación a su finalidad. Comoglio, L. P., cit. (n. 44), pp. 51-53.

${ }^{65}$ CAdiet, L y otros., cit. (n. 41), pp. 289.

${ }^{66}$ Dato arrojado por un estudio empírico. Véase: Doing Business in a More Transparent World (Washington, The World Bank, 2012) p. 103, disponible en www. doingbusiness.org [consultada el 15 de septiembre de 2015]. En cuanto al reclamo general sobre la crisis de la justicia civil véase: Zuckerman, A., Civil Justice in Crisis Comparative Perspectives of Civil Procedure (Oxford, Oxford University Press, 1999).

${ }^{67}$ Introducida al ordenamiento italiano a través del decreto legislativo $\mathrm{N}^{\circ}$ 150/2011 de septiembre de 2011, que crea disposiciones complementarias al código de procedimiento civil en materia de reducción y simplificación de los procedimientos civiles de cognición. Disponible en: http://www.normattiva.it/uri-res/N2Ls?urn :nir:stato:decretolegisl:2011-09-01;150@originalev[consultada el 15 de septiembre de 2015].

${ }^{68}$ Como por ejemplo, a través de sucesivas modificaciones al artículo 136 del CPC italiano. La última de noviembre de 2011, que comprende la utilización de correo electrónico certificado, para la comunicación y notificación de los actos y las resoluciones del proceso ordinario, que se extiende a algunos trámites del proceso ejecutivo. Se establece también la mediación obligatoria mediante el Decreto $\mathrm{N}^{\circ}$ 28 , de 4 de marzo de 2010, que establece una ley complementaria en materia de mediación y conciliación obligatoria, y una sanción civil a la parte que no participa 
sentidos $^{69}$ y la disminución de los múltiples procedimientos que hasta el momento de las novísimas reformas ${ }^{70}$ existían, a sólo tres: un procedimiento laboral, otro sumario y otro ordinario, y dentro de éste último se encuentra a su vez el de ejecución. Los procesos de familia e infancia, que no sufren modificación, quedan dentro de los procedimientos especiales, pero mantienen unidad con el ordinario a través de su inclusión correlativa a los anteriores dentro de un mismo texto ${ }^{71}$. En este orden de ideas se optó por la codificación o compilación de todos los cuerpos normativos que contenían los procedimientos señalados bajo una denominación común: Código de procedimiento civil ${ }^{72}$. Así no cabe duda que la legislación italiana comprende dentro de la Justicia civil los problemas de familia e infancia a los que por ende le resultan aplicables los mismos parámetros

de dicho proceso, que no sólo se establece para los temas de familia, sino que otros como comodato, responsabilidad médica, etc.

${ }^{69}$ Dentro de la simplificación se puede notar, por ejemplo, la sinteticidad que se exige en el contenido de algunos actos procesales como la presentación de un recurso de casación que requiere la "exposición sumaria de los hechos de la causa", sin la cual el recurso es desechado al inicio (art. 366 n. 3). Cfr. Finocchiaro, G., Il principio di sinteticità nel proceso civile, en Rivista di Diritto Processuale (2013), p. 865 n. 3.

${ }^{70}$ Los últimos 20 años la justicia italiana ha venido experimentando reformas en el sentido anotado. No obstante, los reclamos y la preocupación, por ejemplo, de la Corte Europea de Derechos Humanos, continúan en torno a la excesiva duración de los litigios. Específicamente, por infracción al artículo 6,1 de la Convención, véase la declaración del Comité de Ministros de 13 de marzo de 2012, $\mathrm{N}^{\circ} 1136$, disponible en: https://wcd.coe.int/rsi/common/index.jsp [consultada el 12 de septiembre de 2015].

${ }^{71}$ Una de las razones de la síntesis ha sido la evolución normativa que desembocó en la proliferación de los diferentes ritos procesales que hasta ese momento no tenían un diseño orgánico que es el que ahora se pretende. Amendolagine, V., Processo civile: la semplificaziones dei riti (s. l., Wolters Kluwer, 2011), pp. 3-6; CARRATTA, A., La "semplificazione" dei riti e le nuove modifiche del processo civile (Torino, Giappichelli, 2012), pp. 1-7.

${ }^{72}$ Para comprender la figura, la misma confusión que ocurría antes de la reforma en Italia, puede estimarse que sucede en Chile actualmente con los procedimientos de familia e infancia, más en los de adopción y algunos otros sumarios como el de arrendamiento, que están dispersos en diversos cuerpos legales. En particular, no se tiene claridad sobre la ejecución de algunos trámites que no están previstos en el rito señalado en la ley 19.968, sobre todo en lo concerniente a la etapa de prueba y ejecutiva. La supletoriedad del Código de Procedimiento Civil establecida (artículo 27 de la Ley $N^{\circ} 19.968$, de 2004) como salvaguarda a esta situación también resulta insuficiente pues su tenor al parecer obsta la posibilidad de aplicar la supletoriedad a todos los trámites procesales y se refiere únicamente a las disposiciones comunes a todo procedimiento. 
adjetivos generales ${ }^{73}$. Específicamente la tutela judicial de las cuestiones de familia, como se expresó, está entregada a un procedimiento especial por audiencias que se legitima desde la Constitución italiana ${ }^{74}$ y el Código Civil, en éste se específica ritualmente en el título segundo del libro cuarto ${ }^{75}$. En general, en la tramitación de cada uno de los procedimientos establecidos ${ }^{76}$ se observa una suerte de sumarización, atendida la necesidad de urgencia de este tipo de asuntos ${ }^{77}$. Tampoco se ha individualizado un principio de desformalización en aquel.

En cuanto a la protección de los derechos de los niños, el marco referencial de mayor envergadura para la tutela de sus derechos adjetivos que influye todo el cuadro sintético anotado en el párrafo anterior se encuentra

${ }^{73} \mathrm{La}$ referencia a tan importante reforma en Italia es aquí ilustrativa solamente. Pretende solo exponer las vías de solución que otro país, que comparte igual tradición jurídica que Chile, ha adoptado para canalizar de una forma más expedita el rito. Esta reforma en Italia ha dado que hablar, algunos estiman que con su introducción se ha producido una mayor multiplicación y complicación de los procedimientos especiales. CarratTa, A., cit. (n. 71), p. 3.

${ }^{74}$ El texto constitucional (artículo 29) en este punto ofrece protección a la familia, con la singularidad que declara que es aquella que está sentada sobre la base del matrimonio. Lo particular, está dado en que la sociedad moderna cada vez se abre a nuevas formas de constitución de la familia y en el caso italiano, las estadísticas hablan de un creciente menor número de matrimonios. De acuerdo a esa realidad social es que autores hablan de que en los hechos la Constitución usa un término de referencia para aludir al matrimonio y que, por tanto, la tutela del derecho se abre hoy en día a un concepto de familia más amplio. Pomodoro, L. y otros, Manuale di diritto de famiglia e dei minori (Milano, Wolters Kluwer, 2009), pp. 17-22.

${ }^{75}$ Las fuentes del procedimiento de familia e infancia arrancan, indistintamente desde el Código de Procedimiento Civil y el Código Civil, aparte de su fuente constitucional. Donde hay una mayor diseminación de normas, que ha merecido algunas críticas, es en la figura del administrador provisional del incapaz ("aministrazione di sostengo"). Motтola, M. R. y otros, Aspetti processuali e disciplina del diritto di famiglia (Milano, CEDAM, 2013), pp. 863-864.

${ }^{76}$ Las materias son: separación conyugal, interdicción, inhabilitación y administración, declaración de muerte presunta, tutela de menores, interdictos o inhábiles, relaciones patrimoniales entre cónyuges y abusos familiares. Las otras materias como nulidad de matrimonio, alimentos y acciones de filiación caen dentro de la competencia genérica sometida a los trámites del procedimiento ordinario de conocimiento, con las modificaciones que cada ley sustantiva pueda establecer para la materia que se trate. Similar a lo que ocurre en Chile en los pleitos sobre divorcio y alimentos en que la ley sustantiva y adjetiva contiene formas rituales. Hay otros asuntos que resuelven los mismos tribunales por vía voluntaria, tales como sucesión, quiebra, emancipación a favor de niños, etc. Véase: ArCeri, A., Minori e volontaria giurisdizione (Milano, Giuffrè, 2012).

${ }^{77}$ Zatтi, P., Trattato di dirito di famiglia (Milano, Giuffrè, 2010), pp. 545-737. 
en la "Convención Europea de Estrasburgo"78. Desde aquel instrumento se señala que el procedimiento que custodia sus intereses es contencioso, en tanto el mismo sujeto de protección, esto es, el niño, es considerado parte, dentro de un proceso que en su estructura funcional cumple los mismos cánones que un proceso patrimonial ${ }^{79}$. Ambos públicos, de relevancia constitucional $^{80}$ a los que les resultan aplicables iguales consideraciones de protección emanadas del debido proceso ${ }^{81}$.

En Italia no existen aún tribunales de familia ${ }^{82}$ con competencia genérica sobre dichos asuntos conjuntamente con los referidos a la protección de los niños ${ }^{83}$, sino que los tribunales civiles ven ciertas materias ${ }^{84}$, mientras que para la protección de la infancia se encarga otro tribunal (Tribunale per i Minorenni) ${ }^{85}$ cuyas resoluciones cuando son impugnadas son vistas

${ }^{78}$ Stanzione, P. - Sciancalepore, G., Minori e diritti fondamentali (Milano, Giuffrè, 2006), p. 47.

${ }^{79}$ Teniendo en cuenta que necesariamente el proceso debe tener un carácter instrumental respecto al derecho sustancial. Proto PISANI, A., I diritti e le tutele (Roma, Edizioni Scientifiche Italiani, 2009), p. 8.

${ }^{80}$ Cesaro, G., I ruolo del magistrato nel processo minorile tra tutela del minore e rispetto dei diversi ruoli, en CESARO, G. (editor), La tutela dell interesse del minore:deontologie a confronto (Milano, FrancoAngeli, 2007), p. 21.

${ }^{81}$ Turri, G., Finalità del giusto processo minorile e ruolo di parte del minore, en RugGiu, A.- PÈ, A. (editores), Il giusto processo e la protezione del minore (Milano, Franco Angeli, 2011), p. 51.

${ }^{82}$ Cfr. CAPri, F., La specializzazione del gividice come fattores di efficienza della giustizia civile, en Rivista Trimestrale di Diritoo e Procedura Civile (2013), pp. 10141015.

${ }^{83}$ Sobre el particular, para el sistema inglés, véase Partington, M., Introduction to the English Legal System (Oxford, Oxford University Press, 2010), pp. 177-183.

${ }^{84} \mathrm{La}$ falta de especialización del tribunal produce cierta confusión. Similar a la que ocurría en Chile cuando existían tribunales de menores y civiles que se encargaban de materias de familia como la violencia doméstica. Al igual que Chile en antaño, que se cuestionaba la especialización del juez civil en temas atingentes a la familia que incluso causaba el reclamo de los mismos jueces de letras, hoy ocurre en Italia. Sobre todo por la reciente reforma a las acciones de filiación que pasan a ser parte del tribunal civil ordinario. TOMMASEO, F., I procedimenti de potestate e la nuova legge sulla filiazione, en Rivista di Diritto Processuale (2013) 3, pp. 558-572.

${ }^{85}$ Separación de competencias no exenta de críticas por aquellos que opinan que los asuntos extra patrimoniales, estrechamente unidos, como en el caso de los niños y la familia, deben estar sujetos a la especialización tanto del tribunal como de los jueces. Verardo, M., Un processo giusto per la legge o per il bambino?, en RUGGIU, A.Ṗ̀, A. (editores) Il giusto processo e la protezione del minore (Milano, Franco Angeli, 2011), pp. 249-250. Pocar, V. - RONFanI, P., Il giudice e $i$ diritti dei minori (BarI, Laterza, 2004), pp. 39-42. 
por una sección especializada ${ }^{86}$ de la Corte d'Appello, que también se extiende a las controversias sobre familia ${ }^{87}$.

En España, la exposición de motivos de la última gran reforma a la Ley de Enjuiciamiento Civil (ley 1/2000 del 7 de enero, en adelante LEC.) contiene declaraciones que hacían prever mejoras en la tramitación de las causas civiles, en el sentido que allí se anuncia: "La real simplificación procedimental se lleva a cabo con la eliminación de reiteraciones, la subsanación de insuficiencias de regulación y con una nueva ordenación de los procesos declarativos, de los recursos, de la ejecución forzosa y de las medidas cautelares, que busca ser clara, sencilla y completa en función de la realidad de los litigios y de los derechos, facultades, deberes y cargas que corresponden a los tribunales, a los justiciables y a quienes, de un modo u otro, han de colaborar con la Justicia civil."

Como queda de manifiesto, el camino del legislador español para mejorar el proceso civil no se construye sobre la estructura del rito, salvo en lo relativo a la oralidad, sino sobre salvaguardas al ralentí de los procesos, en comparación al modelo anterior. Por ejemplo, en consonancia con el mensaje transcrito, se acortan los plazos para dictar sentencia a 10 o 5 días según las circunstancias indicadas en la norma ${ }^{88}$. También se eliminan las "diligencias para mejor proveer" símil de las medidas para mejor resolver chilenas, dejando en claro que el modelo que se presenta es eminentemente dispositivo ${ }^{89}$, etcétera. Entonces, los remedios apuntan a disminuir

${ }^{86} \mathrm{La}$ especialización de las Cortes de Apelaciones en estas materias es absolutamente necesaria, tanto de la preparación de los jueces habilitados para fallarlos, como de los aspectos orgánicos. Los problemas de la infancia, teniendo en cuenta la importancia de los derechos tutelados en este tipo de asuntos, no pueden resolverse bajo el prisma de jueces que durante toda su experiencia judicial resolvieron casos concerniente a otras jurisdicciones o que pasan de un lapso a otro, es decir, desde problemas de índole patrimonial a otros de carácter criminal. La especialización judicial está completamente justificada por el ordenamiento jurídico internacional y por medio de él, para la mayoría de los ordenamientos de occidente, a través del principio establecido en el artículo primero de la Convención sobre derechos del niño. En su virtud un ser humano menor de 18 años, posee innumerables elementos de conformación de diversa índole, distintos a los que le corresponden a un mayor de edad, que éste debe respetar y que merecen un amparo diferenciado. En el caso chileno, por ejemplo, no es posible que se resuelvan por las Cortes controversias concernientes al derecho de alimentos para niños, con parámetros del derecho penal, sin referencia ni ponderación alguna a la ley de familia e infancia y a la Convención de derechos del niño.

${ }^{87}$ Coffari, A., I diritti dei bambini: un debito con la storia (Milano, Franco Angeli, 2007), pp. 17-19.

${ }^{88}$ Véase artículo $447 \mathrm{~N}^{\circ} 1$ LEC.

${ }^{89}$ De la Oliva Santos, A., El papel del juez en el proceso civil (Santiago, Thomson 
el tiempo de tramitación efectiva, pero no se ha previsto, ni tampoco se hace mención, como en Italia a la libertad de éstas, ni la distinción entre forma y contenido. La única similitud entre ambas naciones se da porque hay comunicabilidad entre la justicia civil patrimonial y el de familia e infancia, a través de la inserción de ambos procedimientos, en la misma codificación.

En España, la protección procesal a la familia está establecida dentro de la LEC. y se establece como un procedimiento especial contenido en el libro IV, título I de dicho cuerpo legal. En él se advierte una segmentación de los asuntos que varían sus trámites procedimentales según se trate de las diversas materias de familia. Así los procesos matrimoniales y de la infancia, poseen un tratamiento distinto a los referidos a la filiación y capacidad. Aquello es natural y se apega necesariamente a la instrumentalidad del proceso y su particularidad en relación al derecho material que encausa. Todas estas materias son vistas por tribunales ordinarios con competencia civil, dentro de los cuales a algunos se ha asignado la facultad de revisar dichas controversias. En dicho país no hay actualmente tribunales especiales de familia ${ }^{90}$.

Los asuntos concernientes a la protección de los niños en situación de desamparo se tramitan generalmente en sede administrativa ${ }^{91}$ (en las entidades públicas destinadas a ello) con conocimiento del Ministerio Fiscal $^{92}$. Sobre las medidas adoptadas en dicho estamento, o en caso de oposición se traba un proceso judicial denominado "control jurisdiccional de las medidas de protección" ${ }^{93}$ Esto constituye una adecuación al sistema vigente antes de la entrada en vigencia de la LEC puesto que hasta ese entonces existía un sistema complejo de protección que venía desde la ley orgánica de protección jurídica del menor de 1996 (LO/ 1996). En

Reuters, 2012), pp. 45-46.

${ }^{90}$ Esto ocasiona propuestas por la Doctrina en orden a la creación de un único tribunal que abarque los problemas de familia e infancia. La necesidad surge a partir de la imperiosa especialización que requiere este tipo de asuntos por los jueces, como ya se ha comentado en este estudio, pero también primordialmente por la carencia de órganos técnicos por parte de los tribunales ordinarios españoles, para orientar la resolución de estas controversias. La única experiencia actual es la existencia de tribunales especiales para resolver la violencia doméstica.

${ }^{91}$ De Palma del Teso, Á., Administraciones públicas y protección de la infancia. En especial, estudio de la tutela administrativa de los menores desamparados (Madrid, Instituto Nacional de la Administración Pública, 2006), pp. 451-458.

${ }^{92}$ Artículo 172 CCEsp.

${ }^{93}$ De la Oliva VÁsquez, A., El acogimiento del menor en situación de desamparo en Morillas, M. y otros (editores), Aspectos actuales de la protección jurídica del menor (Madrid, Aranzadi, 2008), pp. 241-242. 
todos los aspectos se pretende una mayor celeridad en comparación a un proceso ordinario, pero en ningún caso el legislador español ha insertado un principio que pretenda darle flexibilidad, ni tampoco lo ha anunciado expresamente como una característica del mismo.

\section{Conclusiones}

1. Los legisladores fueron prudentes en estimar desde su génesis hasta su instauración que la desformalización no permite al juez omitir, crear, modificar o flexibilizar formas a su voluntad. La apertura a la capacidad de legislar por parte de los jueces, son las consecuencias prácticas que se trató de evitar y que hoy se manifiestan debido, por una parte, a la redacción deficiente de la norma que la contiene y, por la otra, a la excesiva discrecionalidad que los jueces de familia manifiestan en su accionar.

2. Si bien es imposible que se exija a los sentenciadores resolver de maneras similares o poseer iguales criterios sobre los alcances jurídicos de la normas, hay ciertos márgenes que con una dispersión excesiva, como la que se ha manifestado en este estudio, resultan sobrepasados. Ello no sólo conlleva a una confusión que se mantiene en el fuero interno de la judicatura, sino que se exterioriza a una tramitación contradictoria que afecta a los justiciables. Esto plantea cuestiones de lege lata, en tanto la seguridad jurídica e igualdad ante la ley quedan mermadas, y de lege ferenda, porque en base a la problemática develada a través de esta investigación, queda abierta la posibilidad de efectuar correcciones por vía legislativa, a fin de precisar la poca claridad que existe en cuanto a este tópico, por parte de la judicatura.

3. La preclusión, mediante el erróneo entendimiento de la desformalización por parte de los operadores, está siendo mermada en los procesos de familia, sin existir fundamento para ello. El cierre de espacios procesales, acorde con la certeza que el derecho predica, es una salvaguarda de aquella virtud. Si el derecho propugna el orden y la coherencia, el órgano judicial debe transitar por el mismo camino. No es posible, en consecuencia, transgredir una institución que constituye una de las bases del derecho procesal.

4. Es bueno tener en cuenta la experiencia italiana y española en la tramitación de los procedimientos en que se tutelan los derechos de la familia. En ellos no se han enunciado principios en aquellos sectores donde no son necesarios o pueden resultar confusos. Por el contrario, se han tomado caminos concretos que buscan reducir los trámites innecesarios y clarificar y sistematizar toda la normativa procedimental sobre el particular. Aquello es beneficioso en el medio chileno, si se piensa en la gran cantidad de apartados normativos y leyes donde se contiene el 
procedimiento de familia. Todas de diversa data. Por una parte, las Leyes $\mathrm{N}^{\text {os }} 14.908$ (1962) y 16.618 (1967) que contiene fragmentos de formas adecuadas al procedimiento escrito anterior (tribunales de menores), que sin adecuación alguna, se implantan al marco del proceso oral establecido en la ley 19.968 del año 2005. El cuadro se cierra con la supletoriedad que ofrece en Código de procedimiento civil, de corte principalmente dispositivo y con una vigencia de más de cien años.

5. La conclusión final de toda la investigación se vierte en el siguiente axioma: la desformalización es una característica intrínseca al rito establecido en la LTF que está preanunciada en el artículo $9^{\circ}$ de la misma ley. Ello implica que las formas establecidas en el procedimiento que propende a tutelar los derechos de la familia y la infancia, atendidos los bienes que protege, son por sí mismas suficientemente flexibles para otorgarle eficiencia y rapidez a su tramitación. No es una directriz jurídica, tanto por la exégesis del contexto normativo donde el modelo se encuentra inserto, su historia legislativa y las inconveniencias prácticas de estimarlo como tal, habida cuenta de los diversos alcances que la judicatura le confiere a los principios jurídicos, como al contenido dispar que desde esa categoría se le otorga.

\section{BibLIOGRAFÍA}

Alpa, G., I principi generali (Milano, Giuffrè, 2006).

Amendolagine, V., Processo civile: la semplificaziones dei riti (s. 1. , Wolters Kluwer, 2011)

ArCeri, A., Minori e volontaria giurisdizione (Milano, Giuffrè, 2012).

Balena, G., Elementi di diritto processuale civile (Bari, Cacucci, 2006).

Barrientos Grandón, J., El código de la familia (Santiago, Thomson Reuters, 2009).

Belvedere, A., Forma, en Iudica, Giovanni - Zatti, Paolo (editores), Trattato di diritto privato (Milano, Giuffrè, 1994).

Bone, R., Civil Procedure, The Economics of Civil Procedure (New York, Fundation Press, 2003).

Cadiet, L. - Jacques, N. -Amrani Mekri, S., Théorie générale du procès (Paris, Presses Universitaries de France, 2010).

CAPRI, F., La specializzazione del giuidice come fattores di efficienza della giustizia civile, en Rivista Trimestrale di Dirito e Procedura Civile (2013) 3.

Carratta, A., La "semplificaziones" dei riti e le nuove modifiche del processo civile (Torino, Giappichelli, 2012).

Carretta, F., La coherencia en el proceso civil (Santiago, Thomson Reuters, 2013).

Carretta, F., La desformalización del proceso judicial de familia e infancia, en Revista de Derecho de la Pontificia Universidad Católica de Valparaíso, 42 (2014) 1.

CESARO, G., I ruolo del magistrato nel processo minorile tra tutela del minore e rispetto dei diversi ruoli, en CESARO, G. (editor), La tutela dell interesse del minore:deontologie a confronto,(Milano, FrancoAngeli, 2007).

Chiarloni, S., Ragionevolezza costituzionale e garanzie del processo, en Rivista di diritto processuale, 68 (2013 Maggio - Giugno) 3. 
Chiovenda,G., Instituzioni di diritto processuale civile (Napoli, Jovene, 1960), I.

Chiovenda, G., Principi di diritto processuale civile (Napoli, Jovene,1965).

COFfari, A., I diritti dei bambini: un debito con la storia (Milano, FrancoAngeli, 2007).

Cogliandro, G., "Rule of Law", la possibilità del contenuto morale del diritto (Milano, Giuffrè, 2012).

Comoglio, L. P., Il principio di economia processuale (Padova, Cedam, 1980), I.

Comoglio, L. P. - Ferri, C. - Taruffo, M., Lezioni sul processo civile (2a edición, Bologna, Il Mulino, 2011).

Cross, R. - Harris, W., Precedente in English Law (Oxford, Clarendon Press, 1991).

Dalla Massara, T. - Vaccari, M. (editores), Economia processuale e comportamento delle parti nel processo civile (Napoli, Jovene, 2012).

De la Oliva Santos, A., El papel del juez en el proceso civil (Santiago, Thomson Reuters, 2012).

De la Oliva Vásquez, A., El acogimiento del menor en situación de desamparo en MoRILLAS, M. y otros (editores), Aspectos actuales de la protección jurídica del menor (Madrid, Thomson Aranzadi, 2008).

De Palma del Teso, Á., Administraciones públicas y protección de la infancia. En especial, estudio de la tutela administrativa de los menores desamparados (Madrid, Instituto Nacional de la Administración Pública, 2006).

DE SANTIS, F., Riforme processuale e disponibilitá del regime preclusivo, en Studi di diritto civile in onore di Giuseppe Tarzia (2005).

Denti, V., Un progetto per la giustizia civile (Bologna, Il Mulino, 1982).

Di Benedetto, G. - Bellano, S., I linguaggi del processo (Milano, Giuffrè, 2002).

Donati, A., "Rule of law", "Comon law". Lineamenti (Milano, Giuffrè, 2010).

Draetta, U., Principi di diritto delle organizzazioni internazionali (Milano, Giuffrè, 2012).

Dworkin, R., Talking Rights Seriously (London, Bloombsbury, 2013).

ESSER, J., Principio y norma en la elaboración jurisprudencial del derecho privado (traducción de E. Valentí, Barcelona, Bosch, 1961).

Finocchiaro, G., Il principio di sinteticità nel proceso civile, en Rivista di Diritto Processuale (Luglio-Ottobre de 2013).

FrassinetTi, A., La notificaziones nel processo civile (Milano, Giuffrè, 2012).

Gometz, G., La certezza giuridica come prevedibilità. (Torino, Giappichelli, 2005).

Guastini, R., Distinguendo ancora (Madrid, Marcial Pons, 2013).

Losano, M., Sistema e struttura nel diritto. Dalle origini alla Scuola storica (Milano, Giuffrè, 2002), I.

Luiso, F., Diritto processuale civile (Milano, Giuffré, 2007).

Luzzati, C., Principi e principi. La genericità nel diritto (Torino, Giappichelli, 2012).

MacCormick, N., Intitutions of Law (Oxford, Oxford University Press, 2007).

Malleson, K. - Moules, R., The Legal System (4ª edición, Oxford, Oxford University Press, 2010.)

Martino, R. - Panzarola, A., Commentario alle riforme del processo civile dalla semplificaziones dei riti al decreto sviluppo (Torino, Giappichelli, 2013).

Monteleone, G., Preclusioni e giusto proceso: due concetti incompatibili en BongIorNO, G. (editor), Studi in onore di Carmine Punzi, (Torino, Giappichelli, 2008).

Monteleone, G., Manuale di diritto processuale civile (Milano, CeDAM. 2009), I.

Negri, A., Alle origini del formalismo giuridico, (Padova, CEDAM, 1962) 
Partington, M., Introduction to the English Legal System (Oxford, Oxford University Press, 2010).

Pocar, V. - Ronfani, P., Il giudice e i diritti dei minori (Roma, Laterza, 2004).

Pomodoro, L. - Giannino, P. - Avallone, P., Manuale di diritto de famiglia e dei minori (Milano, Wolters Kluwer, 2009).

Posner, R., How Judges Think (Cambridge, Harvard University Press, 2008).

Posner, R., Reflections on Judging (Cambridge, Harvard University Press, 2013).

Proto Pisani, A., I diritti e le tutele (Roma, Edizioni Scientifiche Italiani, 2009).

Redenti, E., Diritto processuale civile (Milano, Giuffré, 1957), I.

Romero Seguel, A., La jurisprudencia de los tribunales como fuente del derecho (Santiago,

Editorial Jurídica de Chile, 2004).

Ross, A., On Law and Justice (New Jersey, Clark, 1959).

SASSANI, B., Impugnativa dell atto e disciplina del rapporto (Padova, CEDAM, 1988).

SASSANI, B., Codice di procedura civile e leggi complementari (Milano, Guiffrè, 2014).

Schauer, F., Playing by the Rules (Oxford, Clarendon Law Series, 1991).

Stanzione, P. - Sciancalepore, G., Minori e diritti fondamentali (Milano, Giuffrè, 2006.

Tesoriere, G., Contributo allo studio delle preclusioi nel proceso civile (Padova, CEDAM, 1983).

Thomas, E. W. The Judicial Process (New York, Cambridge University Press, 2005).

TOMMASEO, F., I procedimenti de potestate e la nuova legge sulla filiazione, en Rivista di Diritto Processuale (Maggio-Giugno, 2013) 3.

TURRI, G., Finalità del giusto processo minorile e ruolo di parte del minore, en RUGGIU, A. - PÈ, A. (editores), Il giusto processo e la protezione del minore (Milano, Franco Angeli, 2011).

VeraRdo, M., Un processo giusto per la legge o per il bambino? en Il giusto processo e la protezione del minore (Milano, Franco Angeli, 2011).

VIOLA, L., La semplificazione dei riti civili (Milano, CEDAM, 2011).

ZatTi, P., Trattato di diritoo di famiglia (Milano, Giuffrè, 2010).

Zuckerman, A., Civil Justice in Crisis. Comparative Perspectives of Civil Procedure (Oxford, Oxford University Press, 1999). 
